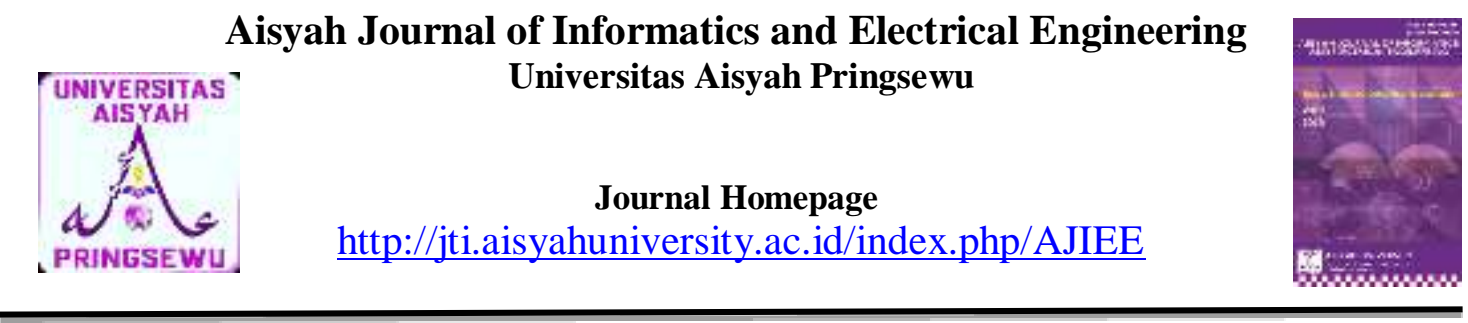

\title{
SISTEM PENUNJANG KEPUTUSA SISTEM PENDUKUNG KEPUTUSAN PENERIMA PROGRAM KELUARGA HARAPAN (PKH) MENGGUNAKAN METODE AHP DAN TOPSIS (Studi Kasus : Kelurahan Sribasuki Kotabumi)
}

\author{
Fery $\operatorname{Irawan}^{1}$ \\ ${ }^{1}$ Magister Teknik Informatika, IlmuKomputer \\ Institut Informatika Dan Bisnis Darmajaya Bandar Lampung \\ E-mail awiimobil@gmail.com
}

\begin{abstract}
Sribasuki Kotabumi Village of North Lampung is one of the places that has implemented conditional cash transfer for family assistance program. It is hoped that a decision can help the village of Sribasuki Kotabumi, criteria for determining the beneficiaries of PKH used are the status of the house, floor area, floor type, wall type, roof type, drinking water source, lighting source, toilet facility, cooking fuel, stool, joint venture, valuable assets. results from threecomparisons of AHP-TOPSIS method, AHP using matrix confusion test with test data from Sribasuki Kotabumi output, from the results that have been tested ahp-topsis methodget the highest resultswith accuracy $82 \%$ accuracy. While the AHP method with accuracy $78 \%$
\end{abstract}

Keywords : AHP, TOPSIS, PKH

\section{ABSTRAK}

Kelurahan Sribasuki Kotabumi Lampung Utara adalah salah satu tempat yang telah menerapkan transfer tunai bersyarat untuk program bantuan keluarga. masalah yang terjadi pada kelurahan Sribasuki Kotabumi hanya berdasarkan sudut pandang pendamping PKH akibatnya banyak warga yang tergolong sangat miskin tidak menerima bantuan PKH. Diharapkan sebuah keputusan dapat membantu kelurahan Sribasuki Kotabumi, kriteria untuk menentukan penerima manfaat PKH yang digunakan yaitu status rumah, luas lantai, jenis lantai, jenis dinding, jenis atap, sumber air minum, sumber penerangan, fasilitas toilet, bahan bakar memasak, tempat tinja, usaha bersama, aset berharga. 
hasil dari tiga perbandingan metode AHP-TOPSIS, AHP menggunakan pengujian confusion matriks dengan data uji dari keluarahan Sribasuki Kotabumi, dari hasil yang telah diuji metode AHP-TOPSIS mendapatkan hasil tertinggi dengan akurasi 82\%. Sedangkan metode AHP dengan akurasi 78\%

Kata Kunci : AHP, TOPSIS, PKH 


\section{PENDAHULUAN}

\subsection{Latar Belakang}

Kelurahan Sribasuki Kotabumi Lampung Utara adalah salah satu tempat yang telah menerapkan transfer tunai bersyarat untuk program bantuan keluarga. masalah yang terjadi pada kelurahan Sribasuki Kotabumi hanya berdasarkan sudut pandang pendamping PKH akibatnya banyak warga yang tergolong sangat miskin tidak menerima bantuan PKH. diharapkan dapat membantu kelurahan Sribasuki Kotabumi, kriteria untuk menentukan penerima bantuan PKH yang digunakan yaitu status rumah, luas lantai, jenis lantai, jenis dinding, jenis atap, sumber air minum, sumber penerangan, fasilitas toilet, bahan bakar memasak, tempat tinja, usaha patungan, aset berharga.

Metode AHP merupakan suatu bentuk model pendukung keputusan dimana peralatan utamanya adalah sebuah hierarki fungsional dengan input utamanya persepsi manusia, yakni dalam hal ini adalah orang yang ahli dalam masalah penerima bantuan PKH atau orang yang mengerti permasalahan bantuan $\mathrm{PKH}$. Sedangkan metode TOPSIS merupakan suatu bentuk metode pendukung keputusan yang didasarkan pada konsep bahwa alternatif yang terbaik tidak hanya memiliki jarak terpendek dari solusi ideal positif tetapi juga memiliki jarak terpanjang dari solusi ideal negatif yang dalam hal ini diharapkan memberikan rekomendasi kelayakan penerima bantuan PKH.

\section{TINJAUAN PUSTAKA}

\subsection{Sistem pendukung keputusan}

Sistem Pendukung Keputusan Sistem pendukung keputusan pertama kali dikenalkan pada awal tahun 1970 oleh Michael S. Scott dengan istilah Management Decision System yang merupakan suatu sistem berbasis komputer yang membantu pengambilan keputusan dengan memanfaatkan data dan model - model untuk menyelesaikan masalah - masalah yang tidak terstruktur. (Kusrini,2007)

\subsubsection{Karakteristik Sistem Pendukung Keputusan}

Karakteristik Sistem pendukung keputusan sebagai berikut : (Saliman, 2011)

A. Sistem pendukung keputusan dirancang untuk membantu pengambil keputusan dalam memecahkan masalah yang bersifat semi terstruktur ataupun tidak terstruktur

B. Dalam proses pengolahannya, sistem pendukung keputusan mengkombinasikan penggunaan model-model / teknik-teknik analisis dengan teknik pemasukan data konvensional serta fungsi-fungsi pencari / interogasi informasi

C. Sistem pendukung keputusan dirancang sedemikian rupa, sehingga dapat digunakan dengan mudah oleh orang yang tidak memiliki dasar kemampuan pengoperasian komputer yang tinggi

Aisyah Journal of Informatics and Electrical Engineering 
D. Sistem pendukung keputusan dirancang dengan menekankan pada aspek fleksibilitas serta kemampuan adaptasi yang tinggi, sehingga mudah disesuaikan dengan kebutuhan pemakai.

\subsubsection{Analytic Hierarchy Process}

AHP (Analytic Hierarchy Process) adalah suatu teori umum tentang pengukuran yang digunakan oleh untuk menemukan skala rasio, baik dari perbandingan berpasangan yang diskrit maupun kontinyu. AHP menguraikan masalah multi faktor atau multi kriteria yang kompleks menjadi suatu hirarki. Hirarki didefinisikan sebagai suatu representasi dari sebuah permasalahan yang kompleks dalam suatu struktur multi level (Mufizar, 2016)

\subsubsection{Tehnique For Order Preference By} Similarity To Ideal Solution

TOPSIS adalah salah satu metode pengambilan keputusan multi kriteria yang pertama kali diperkenalkan oleh Yoon dan Hwang pada tahun 1981. Metode ini merupakan salah satu metode yang banyak digunakan untuk menyelesaikan pengambilan keputusan secara praktis.. (Marlina, 2016)

\subsubsection{Confusion Matrix}

Confusion matrix menggambarkan hasil yang benar dan salah dari suatu model klasifikasi.Nilai confusion matrix biasanya ditunjukkan dalam satuan persen (\%).

(Mahendra, 2019).

\section{METODOLOGI}

Pendekatan yang digunakan dalam penelitian ini adalah penelitian kuantitatif. Penulis melakukan penelitian guna memperoleh data dan informasi yang akurat pada Kelurahan Sribasuki berlokasi di Kotabumi, Lampung Utara.

Populasi dalam penelitian ini adalah seluruh warga yang terdaftar sebagai calon penerima bantuan PKH pada kelurahan sribasuki Kotabumi. Subjek penelitian yang akan menjadi sampel dalam penelitian ini sejumlah 50 (lima puluh) warga

\subsection{Langkah-Langkah Metode AHP-TOPSIS}

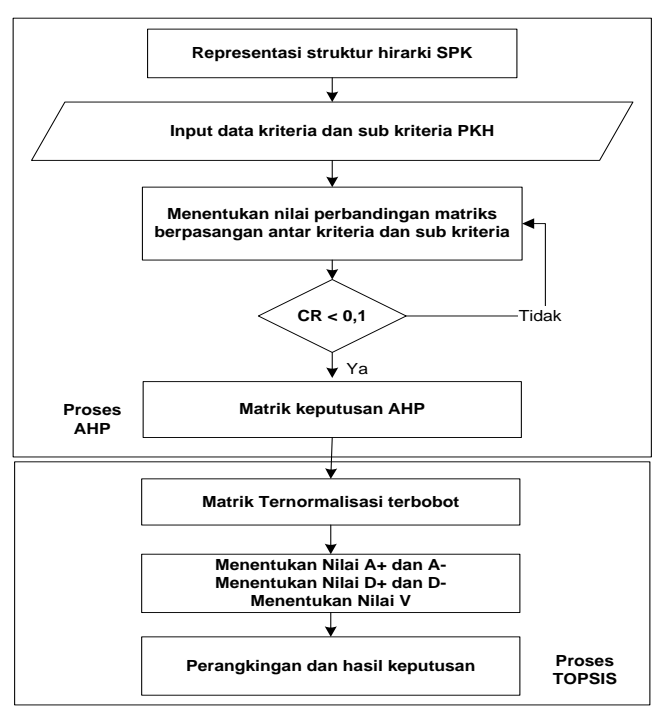

Gambar 3.1 Langkah Metode AHP-TOPSIS

Metode AHP pada penelitian ini digunakan dalam mencari bobot untuk masing-masing 
kriteria serta untuk menguji konsistensi dari bobot kriteria yang ada, Setelah didapatkan bobot untuk tiap-tiap kriteria berdasarkan hasil perhitungan menggunakan AHP, maka selanjutnya akan beralih ke perhitungan metode TOPSIS.

\section{HASIL DAN PEMBAHASAN}

\subsection{Hasil Penelitian}

\subsubsection{Perhitungan Metode AHP}

Tabel. 4.1 Kriteria

\begin{tabular}{|c|c|c|c|}
\hline No & Kriteria & Sub Kriteria & Bobot Nilai \\
\hline \multirow[t]{4}{*}{1} & \multirow[t]{4}{*}{ Status Rumah } & Bebas Sewa & 4 \\
\hline & & Kontrak & 3 \\
\hline & & Milik Orang Tua & 2 \\
\hline & & Milik Sendiri & 1 \\
\hline \multirow[t]{2}{*}{2} & \multirow[t]{2}{*}{ Luas Lantai } & $\leq 8 \mathrm{~m} 2$ & 2 \\
\hline & & $\geq 8 \mathrm{~m} 2$ & 1 \\
\hline \multirow[t]{4}{*}{3} & \multirow[t]{4}{*}{ Jenis Lantai } & Tanah & 4 \\
\hline & & Semen & 3 \\
\hline & & Keramik & 2 \\
\hline & & Granit & 1 \\
\hline \multirow[t]{3}{*}{4} & \multirow[t]{3}{*}{ Jenis Dinding } & Bambu & 3 \\
\hline & & Kayu & 2 \\
\hline & & Tembok & 1 \\
\hline \multirow[t]{3}{*}{5} & \multirow[t]{3}{*}{ Jenis Atap } & Asbes & 3 \\
\hline & & Seng & 2 \\
\hline & & Genteng & 1 \\
\hline \multirow[t]{4}{*}{6} & \multirow[t]{4}{*}{ Sumber Air Minum } & Sungai & 4 \\
\hline & & Sumur & 3 \\
\hline & & Ledeng & 2 \\
\hline & & Isi ulang & 1 \\
\hline \multirow[t]{2}{*}{7} & \multirow[t]{2}{*}{ Sumber Penerangan } & Listrik PLN & 1 \\
\hline & & Non Listrik PLN & 2 \\
\hline \multirow[t]{3}{*}{8} & \multirow[t]{3}{*}{ Fasilitas Jamban } & Tidak Ada & 3 \\
\hline & & Umum & 2 \\
\hline & & Sendiri & 1 \\
\hline \multirow[t]{4}{*}{9} & \multirow[t]{4}{*}{ Bahan Bakar Masak } & Kayu & 4 \\
\hline & & Minyak Tanah & 3 \\
\hline & & Gas LPG & 2 \\
\hline & & Listrik & 1 \\
\hline \multirow[t]{3}{*}{10} & \multirow[t]{3}{*}{ Tempat Akhir Tinja } & Lubang Tanah & 3 \\
\hline & & Sungai & 2 \\
\hline & & Tangki & 1 \\
\hline
\end{tabular}

Langkah selanjutnya adalah melakukan tahapan metode AHP

\section{A. Hirarki Penerima PKH}

B. Perbandingan Berpasangan Kriteria

Berikut ini matrik perbandingan berpasangan yang didapatkan dari penilaian skala 1 (satu) sampai 9 (sembilan) pada tabel 4.2
Tabel 4.2 Matriks Perbandingan

\begin{tabular}{|l|c|c|c|c|c|c|c|c|c|c|c|c|}
\hline Kriteria & $C 1$ & $C 2$ & $C 3$ & $C 4$ & $C 5$ & $C 6$ & $C 7$ & $C 8$ & $C 9$ & $C 10$ & $C 11$ & $C 12$ \\
\hline$C 1$ & 1,00 & 5,00 & 5,00 & 5,00 & 5,00 & 5,00 & 5,00 & 5,00 & 5,00 & 5,00 & 5,00 & 5,00 \\
\hline$C 2$ & 0,20 & 1,00 & 2,00 & 2,00 & 2,00 & 2,00 & 2,00 & 2,00 & 2,00 & 2,00 & 2,00 & 2,00 \\
\hline$C 3$ & 0,20 & 0,50 & 1,00 & 2,00 & 2,00 & 2,00 & 2,00 & 2,00 & 2,00 & 2,00 & 2,00 & 2,00 \\
\hline$C 4$ & 0,20 & 0,50 & 0,50 & 1,00 & 2,00 & 2,00 & 3,00 & 3,00 & 3,00 & 3,00 & 3,00 & 3,00 \\
\hline$C 5$ & 0,20 & 0,50 & 0,50 & 0,50 & 1,00 & 3,00 & 2,00 & 2,00 & 2,00 & 3,00 & 3,00 & 3,00 \\
\hline$C 6$ & 0,20 & 0,50 & 0,50 & 0,50 & 0,33 & 1,00 & 1,00 & 3,00 & 1,00 & 3,00 & 5,00 & 5,00 \\
\hline$C 7$ & 0,20 & 0,50 & 0,50 & 0,33 & 0,50 & 1,00 & 1,00 & 2,00 & 2,00 & 2,00 & 3,00 & 5,00 \\
\hline$C 8$ & 0,20 & 0,50 & 0,50 & 0,33 & 0,50 & 0,33 & 0,50 & 1,00 & 1,00 & 1,00 & 5,00 & 5,00 \\
\hline$C 9$ & 0,20 & 0,50 & 0,50 & 0,33 & 0,50 & 1,00 & 0,50 & 1,00 & 1,00 & 3,00 & 5,00 & 5,00 \\
\hline$C 10$ & 0,20 & 0,50 & 0,50 & 0,33 & 0,33 & 0,33 & 0,50 & 1,00 & 0,33 & 1,00 & 3,00 & 2,00 \\
\hline$C 11$ & 0,20 & 0,50 & 0,50 & 0,33 & 0,33 & 0,20 & 0,33 & 0,20 & 0,20 & 0,33 & 1,00 & 2,00 \\
\hline$C 12$ & 0,20 & 0,50 & 0,50 & 0,33 & 0,33 & 0,20 & 0,20 & 0,20 & 0,20 & 0,50 & 0,50 & 1,00 \\
\hline
\end{tabular}

\section{Konsistensi CR}

Berikut ini tahapan dalam perhitungan

konsistensi CR

\section{Bobot Prioritas}

Berikut ini bobot prioritas dan jumlah baris dari kriteria pada tabel 4.3 yang didapat dari hasil penjumlahan baris dan dibagi dengan jumlah kriteria

Tabel 4.3 Bobot Prioritas

\begin{tabular}{|c|c|c|}
\hline $\begin{array}{c}\text { jumlah } \\
\text { Baris }\end{array}$ & $\begin{array}{c}\text { Bobot } \\
\text { Prioritas }\end{array}$ & Lamda \\
\hline 3,371 & 0,281 & 13,798 \\
\hline 1,195 & 0,100 & 14,005 \\
\hline 1,070 & 0,089 & 14,089 \\
\hline 1,194 & 0,099 & 13,938 \\
\hline 0,993 & 0,083 & 13,835 \\
\hline 0,879 & 0,073 & 13,275 \\
\hline 0,791 & 0,066 & 13,405 \\
\hline 0,646 & 0,054 & 13,028 \\
\hline 0,760 & 0,063 & 13,083 \\
\hline 0,472 & 0,039 & 13,097 \\
\hline 0,334 & 0,028 & 12,977 \\
\hline 0,295 & 0,025 & 13,048 \\
\hline
\end{tabular}

Nilai lamda yang dihasilkan dari perkalian matrik dengan nilai bobot prioritas. 
Langkah selanjutnya menghitung jumlah total lamda adalah 161,577 yang akan digunakan untuk mencari $\lambda$ Maks sebagai berikut :

$$
\lambda \text { maks }=\frac{161,577}{12}=13,465
$$

Langkah selanjutnya adalah menghitung CI dan CR sebagai berikut :

A. Menghitung Consistency index (CI)

$$
=\frac{(13,465-12)}{12-1}=0,133
$$

B. Menghitung Consistency Ratio (CR)

$$
\begin{aligned}
& C R=\frac{C I}{I R} \\
& C R=\frac{0,133}{1,48}=0,090
\end{aligned}
$$

Berdasarkan hasil CR bernilai kurang dari 0,1 maka hasil perhitungan dapat dinyatakan benar (Konsisten).

Langkh selanjutnya adalah perhitungan metode topsis dengan langkah - langkah berikut :

Tabel 4.4 Matrik Keputusan

\begin{tabular}{|l|c|c|c|c|c|c|c|c|c|c|c|c|}
\hline Alternatif & C1 & C2 & C3 & C4 & C5 & C6 & C7 & C8 & C9 & C10 & C11 & C12 \\
\hline A1 & 1 & 2 & 3 & 1 & 1 & 3 & 1 & 1 & 4 & 1 & 2 & 2 \\
\hline A2 & 3 & 1 & 3 & 1 & 1 & 3 & 1 & 1 & 2 & 1 & 2 & 2 \\
\hline A3 & 3 & 1 & 3 & 1 & 1 & 1 & 1 & 1 & 2 & 1 & 2 & 2 \\
\hline A4 & 1 & 1 & 3 & 2 & 2 & 3 & 1 & 1 & 4 & 1 & 2 & 2 \\
\hline A5 & 2 & 1 & 2 & 1 & 1 & 1 & 1 & 1 & 2 & 1 & 1 & 2 \\
\hline
\end{tabular}

Langkah selanjutnya menghitung total nilai matrik keputusan didapatkan dari nilai keseluruhan subkriteria kemudian diakar

\section{Normalisasi Matrik}

Menghitung Jumlah normalisasi didapat dari hasil nilai subkriteria dibagi dengan jumlah total matrik keputusan

\section{Matrik Normalisasi Terbobot}

Menghitung Normalisasi terbobot dengan cara mengalikan setiap elemen pada matriks normalisasi dengan bobot yang diperoleh pada proses AHP. Pada tabel 4.5

Tabel 4.5 Matriks Normalisasi Terbobot

\begin{tabular}{|c|c|c|c|c|c|c|c|c|c|c|c|c|}
\hline Alternatif & C1 & C2 & C3 & C4 & C5 & C6 & C7 & C8 & C9 & C10 & C11 & C12 \\
\hline A1 & 0,247 & 2,435 & 1,789 & 1,048 & 1,260 & 2,827 & 2,145 & 2,628 & 3,292 & 3,592 & 5,659 & 5,485 \\
\hline A2 & 0,740 & 1,218 & 1,789 & 1,048 & 1,260 & 2,827 & 2,145 & 2,628 & 1,646 & 3,592 & 5,659 & 5,485 \\
\hline A3 & 0,740 & 1,218 & 1,789 & 1,048 & 1,260 & 0,942 & 2,145 & 2,628 & 1,646 & 3,592 & 5,659 & 5,485 \\
\hline A4 & 0,247 & 1,218 & 1,789 & 2,096 & 2,521 & 2,827 & 2,145 & 2,628 & 3,292 & 3,592 & 5,659 & 5,485 \\
\hline A5 & 0,494 & 1,218 & 1,193 & 1,048 & 1,260 & 0,942 & 2,145 & 2,628 & 1,646 & 3,592 & 2,829 & 5,485 \\
\hline
\end{tabular}

3. Solusi Ideal Positif dan Solusi Ideal Negatif

Tahap ini mencari nilai minimum dan maksimun dari setiap kriteri yang ditunjukkan pada Tabel 4.6

Tabel 4.6 Ideal Positif dan Ideal Negatif

\begin{tabular}{|l|l|l|l|l|l|l|l|l|l|l|l|l|}
\hline Kriteria & $\mathrm{Cl}$ & $\mathrm{C2}$ & $\mathrm{C3}$ & $\mathrm{C} 4$ & $\mathrm{C5}$ & $\mathrm{C6}$ & $\mathrm{C7}$ & $\mathrm{C8}$ & $\mathrm{C9}$ & $\mathrm{C1}$ & $\mathrm{Cl1}$ & $\mathrm{Cl}$ \\
\hline
\end{tabular}

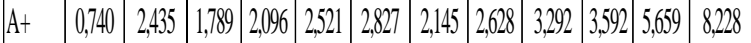

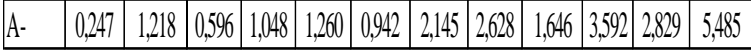

4. Jarak Solusi Ideal Positif dan Solusi Ideal Negatif

Tahap ini dengan cara penjumlahan seluruh nilai kuadrat dari nilai matriks normalisasi terbobot subkriteria pada tabel 4.7

Tabel 4.7 Jarak Solusi Ideal Positif dan Solusi Ideal Negatif

\begin{tabular}{|l|c|c|}
\hline Alternatif & D + & D - \\
\hline A1 & 4,048 & 4,144 \\
\hline A2 & 3,795 & 3,636 \\
\hline A3 & 4,237 & 3,110 \\
\hline A4 & 3,041 & 4,287 \\
\hline A5 & 5,136 & 0,645 \\
\hline
\end{tabular}

5. Hasil Keputusan

Cara menghitung kedekatan terhadap solusi 
ideal positif dan negatif adalah membagi antara solusi ideal negatif dengan penjumlahan antara solusi ideal negatif dengan positif pada tabel 4.8

Tabel 4.8 Hasil keputusan

\begin{tabular}{|l|c|c|}
\hline Alternatif & Hasil & Keputusan \\
\hline A1 & 0,506 & Layak \\
\hline A2 & 0,489 & Layak \\
\hline A3 & 0,423 & Layak \\
\hline A4 & 0,585 & $\begin{array}{c}\text { Layak } \\
\text { A5 }\end{array}$ \\
\hline
\end{tabular}

\subsection{Pembahasan}

Pengujian akurasi sistem terhadap data alternatif penerima bantuan PKH dilakukan dengan cara membandingkan hasil keputusan sistem dengan hasil keputusan Kelurahan Sribasuki. Pengujian akurasi menggunakan Confusion Matrik untuk menguji perbandingan metode AHP-TOPSIS dan AHP sebagai berikut :

1. Pengujian Metode AHP-TOPSIS

Hasil pengujian dilakukan dengan jumlah 50 sampel warga Kelurahan Sribasuki pada tabel 4.9

Tabel 4.9 Pengujian Metode AHP-TOPSIS

\begin{tabular}{|c|c|c|c|}
\hline $\mathrm{TP}$ & 33 & Accuracy & $82 \%$ \\
\hline $\mathrm{TN}$ & 8 & Precission & $83 \%$ \\
\hline FP & 7 & Recall & $94 \%$ \\
\hline $\mathrm{FN}$ & 2 & Specificity & $53 \%$ \\
\hline
\end{tabular}

2. Pengujian Metode AHP

Hasil pengujian dilakukan dengan jumlah 50 sampel warga Kelurahan Sribasuki pada tabel 4.10
Tabel 4.10 Pengujian Metode AHP

\begin{tabular}{|l|c|c|c|c|}
\hline TP & 28 & & Accuracy & $78 \%$ \\
\cline { 1 - 1 } TN & 11 & Precission & $93 \%$ \\
\hline FP & 2 \\
\cline { 1 - 1 } FN & 9 & Recall & $76 \%$ \\
\cline { 1 - 1 } & Specificity & $85 \%$ \\
\hline
\end{tabular}

\section{PENUTUP}

\subsection{Kesimpulan}

Dari hasil penelitian yang dilakukan, dapat diambil kesimpulan bahwa pengujian menggunakan confusion matrik dengan data uji 50 sampel warga kelurahan sribasuki dengan menggunakan kriteria status rumah, luas lantai, jenis lantai, jenis dinding, jenis atap, sumber air minum, sumber penerangan, fasilitas toilet, bahan bakar memasak, tempat tinja, usaha bersama, aset berharga. Dari hasil yang dilakukan oleh penulis, pengujian metode AHP menghasilkan accuracy 78\%, Metode AHPTOPSIS $82 \%$, Berdasarkan yang didapat dari perbandingan metode yang telah diuji bahwa kombinasi metode AHP-TOPSIS memiliki accuracy tertingi dengan nilai $82 \%$.

\subsection{Saran}

1. Dari hasil penelitian yang telah dilakukan saran yang bisa digunakan untuk penelitian yang lebih lanjut disempurnakan dengan memilih penilaian yang lebih akurat atau menggunakan metode yang lain dan daerah penelitian diperluas menjadi lebih luas.

2. Keterbatasan lain dari hasil penelitian ini 
adalah hanya uji coba untuk menilai tingkat akurasi penggunaan metode AHP dan TOPSIS, Agar penelitian ini dapat memberikan kontribusi yang lebih besar, disarankan untuk dikembangkan dengan suatu alat bantu berupa software

\section{DAFTAR PUSTAKA}

Chamid, A. A., \& Murti, A. C. 2017. Kombinasi Metode Ahp Dan Topsis Pada Sistem Pendukung Keputusan. Prosiding SNATIF, 115-119.

Eniyati, S. 2011. Perancangan Sistem Pendukung Pengambilan Keputusan untuk Penerimaan Beasiswa dengan Metode SAW (Simple Additive Weighting). Dinamik, 16(2).

Fadlan, M., \& Muhammad, M. 2017. Terapan Kombinasi Metode Topsis Dan Analytical Hierarchy Process Pada Perekomendasian Penerima Beasiswa Peningkatan Prestasi Akademik (Studi Kasus pada STMIK PPKIA Tarakanita Rahmawati). Simetris: Jurnal Teknik Mesin, Elektro dan Ilmu Komputer, 8(2), 663-670.

Kusrini. 2007. Konsep dan Aplikasi Sistem Pendukung Keputusan. Yogyakarta: Andi

Mahendra, G. S., \& Aryanto, K. Y. E. 2019. SPK Penentuan Lokasi ATM Menggunakan Metode AHP dan SAW. Jurnal Nasional Teknologi dan Sistem Informasi, 5(1), 4956.

Marlina, M., Yusnaeni, W., \& Indriyani, N. 2017. Sistem Pendukung Keputusan Pemilihan Siswa Miskin Menggunakan Metode Analytical Hierarchy Process (AHP). Creative Information Technology Journal, 4(1), 30-44.

Mufizar, T., Anwar, D. S., \& Dewi, R. K. 2016. Pemilihan Calon Penerima Bantuan Siswa
Miskin Menggunakan Metode Analytical Hierarchy Process (AHP). Creative Information Technology Journal, 4(1), 3044.

Petunjuk Teknis Penyaluran Bantuan Sosial Non Tunai Program Keluarga Harapan Tahun 2019

Saaty, Thomas, L., 1994. The Analytical Hierarchy Process. Yogyakarta: Ardana Media.

Sri Kusumadewi, dkk. 2006. Fuzzy MultiAttribute Decision Making (Fuzzy MADM). Yogyakarta: Graha Ilmu.

Yoon, K.P. and Hwang, C.L., 1995. Multiple attri bute decision making: an introduction (Vol.104). Sage publications 